\title{
Analysis of the Use Effectiveness of Lighting Lamps Type for Household Needs
}

\author{
Muhammad $\operatorname{Amin}^{1}$ and Nelson Sinaga ${ }^{2}$ \\ \{ aminunimed@unimed.ac.id ${ }^{1}$, nelson.s@gmail.co.id ${ }^{2}$ \} \\ Faculty of Engineering, Universitas Negeri Medan, Indonesia ${ }^{1,2}$
}

\begin{abstract}
Lighting is very important in various activities in the household, so it becomes dominant in the review of electricity consumption needs. The problems faced by consumers in choosing the use of lighting generally only choose based on the type of lamp which is cheaper, without considering the quality of light and electrical energy used. This study aims to find profiles several types of lights based on the strength of the light produced, the use of electrical energy, and its sensitivity to lower voltage sources. The results of the study recommend a type of lamp that is considered efficient for users. The research method uses experimental approaches. The study was conducted by testing the strength of the light produced, the amount of electrical power used, and the sensitivity to lower voltage sources. Data collection techniques are carried out by measurement and testing. Data analysis was carried out with a quantitative approach and continued with qualitative analysis. The results showed that, (1) the types of Light Emitting Diode (LED) lamps produce better light power compared to Energy Saving Lights (ESL) at the same electrical power consumption, and (3) LED lighting components have better capability in facing a lower voltage source.
\end{abstract}

Keywords: Lighting, energy saving, illumination

\section{Introduction}

One of the main needs for electric power in human life is for lighting needs. Almost all human activities both day and night must use lighting, so with such a large amount, it will definitely be very much in need of very large electricity usage [1] . The magnitude of the need for lighting, coupled with the development of a variety of lighting products, so that the number and type of lighting circulating in the market is very large. This happens because the creation of energy saving lighting is something that is considered very important in an effort to meet human needs. The problem that arises with the presence of various types of lighting brand products on the market, is the lack of information on the characteristics of the lights, so that consumers do not have references in choosing according to their needs. Consumers or users do not have information that whether the circulating lights all really have high efficiency, or whether a type of lamp is better compared to similar lights with different brands.

The need for lighting in a household must consider the electrical power used to produce the needed power. The ability of a lamp that must be known to produce light is its light efficacy. Light efficacy is the ratio of the brightness of each watt, the power can be a light flux from the source output, or it can be the total electric power used by the source. The discovery of sharing types of lighting today is very helpful for consumers in meeting their needs. There 
are several types of lights circulating in the market, although some of them have started to be abandoned by the management, such as incandescent lamps which are considered inefficient anymore, Tubes Lamp (TL) or full fluorescent lamps are no longer used because in addition to being environmentally unfriendly also more electricity consumption high. The types of lights that are more widely used by consumers today include ESL and LED types.

ESL is a type of fluorescent lamp that uses the principle of the process of fluorescent mineral glow where minerals are exposed to ultraviolet light and then react with gas inside the lamp, which produces ultraviolet light. Ultraviolet light then acts with phosphorus, which is a mixture of minerals that line the inside of the light bulb. Whereas LEDs are special semiconductor diodes. LEDs consist of a semiconductor material chip that is fully charged, or dop, with impurities to create a structure called p-n junction. The wavelength of the light emitted, and its color, depends on the difference in the energy band from the material that forms the $p-n$ junction. The LED chip has positive and negative poles $(p-n)$ and will only light up when given an advanced current. This is because LEDs are made of semiconductor material which will only allow electric current to flow in one direction and not in the opposite direction. Light on an LED is electromagnetic energy emitted in a visible portion of the spectrum [2][3]. Characteristics of LED include: Has a longer service life than ordinary lights, can achieve durability of up to 30 thousand hours, has energy efficiency of up to 80-90 percent, is able to work at low electrical voltages, the light produced is not hot.

To obtain information about a product that has good quality, conformity to consumer needs, then of course it can be obtained from the results of testing and research that it does. The results of the study by [4][5] found that the type of LED lights had the best effectiveness compared to the types of fluorescent lamps and incandescent lamps, because they had the smallest level of energy discharge with an average efficiency of $32 \%$ and produce large lighting intensity with an average of 30 lux. [6] confirmed that the lumen / watt value of an LED is the binning value that the LED has, so the smaller the binning value the better the quality of the lamp.

Based on these conditions and facts, the study in this study was conducted to find out, the characteristics of various types of lamps that are circulating in the market, especially those related to ESL and LED, in order to enrich the information to the user community in order to choose according to their needs. The findings in this study will find a type of lamp that is more effective for producing light and lower use of electric power, and also determines the sensitivity level of each type of lamp to reducing the voltage source. This research will certainly provide information to students as a reference in the study of the field of lighting installation.

\section{Methodology}

This study uses an experimental approach. The research was carried out by using measuring instruments in the laboratory such as lux measuring instruments, wattmeter, voltmeter, amperage meter, $\cos \varphi$ meter and other equipment such as voltage regulators and dark room settings. The measurement of the strength of the light produced by the lamp is carried out in the dark room, with a measurement distance between the point of the light and a 2.5-meter measuring instrument. The measurement of the strength of light is carried out at a voltage variation that is gradual up to the normal voltage. The data generated from the 
experiment will be described based on the characteristics of the lamp being tested according to the type of characteristics planned.

The type of lamp that is the research sample consists of types of ESL and LED lamps. Whereas the lamp brand which is the research sample consists of: Hannochs, Philips, NVC, Sun Free, Omai, and Sun Sonic. The number of lights that became the research sample amounted to 100 lights. Data analysis was carried out quantitatively and descriptively. The data obtained are grouped, presented in the form of data that is easy to read, then used to describe the characteristics of the type of lamp being tested. The resulting data is also used as a comparison between the same type of lamp from different products. The different test used is a different type of parametric test if the data requirements are met, but if the data requirements are not met for the parametric test, a nonparametric difference test is used.

\section{Result and Discussion}

\subsection{Profile of Electric Power Usage and Strong Lamp Lighting}

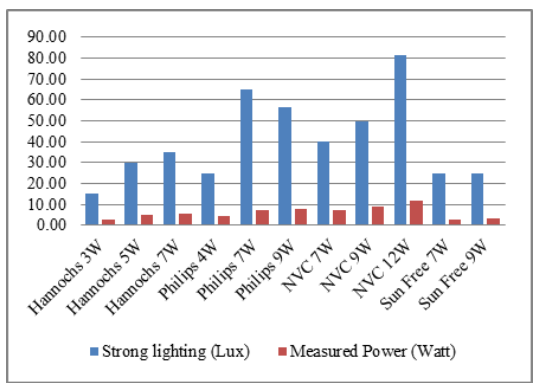

Fig. 1. Profile of Electric Power and Strong Use of LED Lighting.

The measurement results on the use of electric power and the lighting power of each lamp tested at normal voltage indicate that the types of LED lights for each brand produce different strong lighting characteristics. The measurement results show that Hannochs lamp types and NVC lamp types tend to produce relatively linear characteristics between the use of electric power and the lighting produced by the lamp, but for philips and sun free lamps, the characteristics are not linear between the use of electric power and the light produced light. This condition can be seen in Figure 1.

In the same condition the measurement of each type of ESL lamp shows the results of different lighting strong characteristics (Figure 2). 


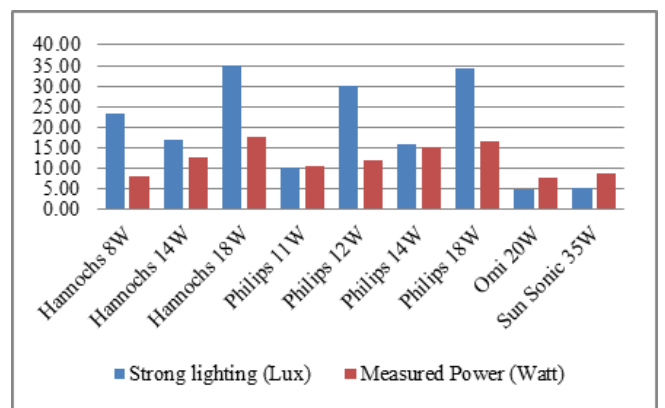

\subsection{Sensitivity Profile of Lights Against Electrical Voltage}

Fig. 2. Profile of Electric Power Usage and Strong ESL Lighting

Based on the results of testing carried out with voltage changes supplying $3 \mathrm{~W}, 4 \mathrm{~W}$, and $5 \mathrm{~W}$ lights, the data obtained as shown in Figure 4. From Figure 4 it can be seen that the types of $3 \mathrm{~W}$ and $5 \mathrm{~W}$ hannochs lamps can produce 15 lux light at 150 Volt, while lamp Philips 4W type can produce light after obtaining a 200 Volt electric voltage. This shows that for a small type of LED light, Hannochs type of lamp shows better sensitivity, because it can turn on at 150 volt.

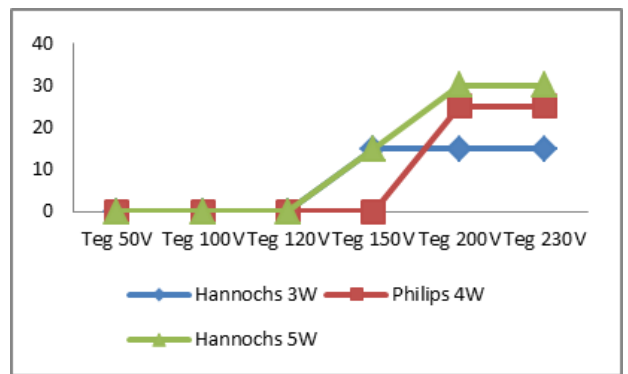

Fig. 3. Sensitivity Profile of LED Lights 3W, 4W and 5W Against Changes in Electrical Voltage

Furthermore, based on the results of testing carried out with voltage changes supplying the 7W lamp, data is obtained as shown in Figure 5. From Figure 5, it can be seen that the type of philips lamp shows the best lighting profile, because the type of Philips lamp can produce 45 lux at a voltage of 100 Volt. When viewed from sensitivity to electrical stresses, the type of NVC lamp shows the ability to produce light at a lower voltage at 50 Volt which is capable of producing 10 lux illumination, although this type of lamp is only able to produce 40 lux of light at normal voltage. and will stabilize starting at 120 Volt.

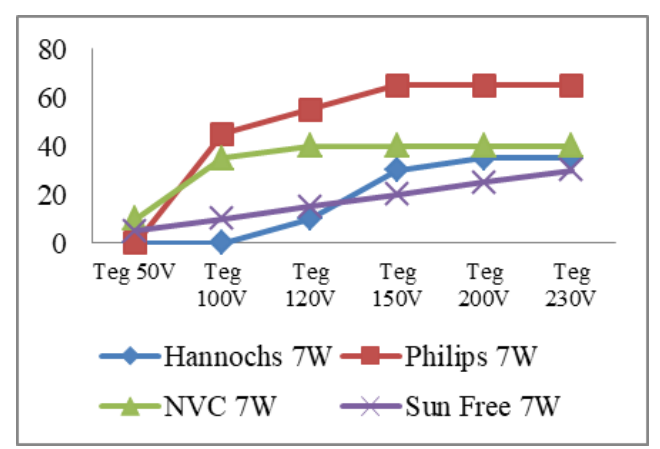


Fig. 4. 7W LED Lamp Sensitivity Profile Against Electricity Changes

The test results are carried out with voltage changes supplying $9 \mathrm{~W}$ and $12 \mathrm{~W}$ lamps, the data obtained as shown in Figure 6. From Figure 6 it can be seen that for the $9 \mathrm{~W}$ lamp power, the type of philips lamp shows the best lighting profile, because the type of Philips lamp can produce 45 lux light at 100 Volt voltage. When viewed from sensitivity to electrical stresses, the type of sun free $9 \mathrm{~W}$ lamp shows the ability to produce light at a lower voltage at 50 Volt which is capable of producing 5 lux illumination power, although this type of lamp is only capable of producing 30 lux illumination at voltage normal, and will produce light according to the amount of voltage received.

Based on the results of testing carried out with voltage changes supplying ESL 8W, $11 \mathrm{~W}$, $12 \mathrm{~W}$ and $14 \mathrm{~W}$ lights, data is obtained as shown in Figure 7. From Figure 7 it can be seen that all types show relatively similar sensitivity to voltage characteristics, where all types of lights produce light starting at a 100 Volt supply voltage. From the data illustrated, it is also seen that the $8 \mathrm{~W}$ hannochs lamps show the ability to produce stronger lighting characteristics that are better when compared to the types of ESL lamps with $11 \mathrm{~W}$ and $14 \mathrm{~W}$ power.

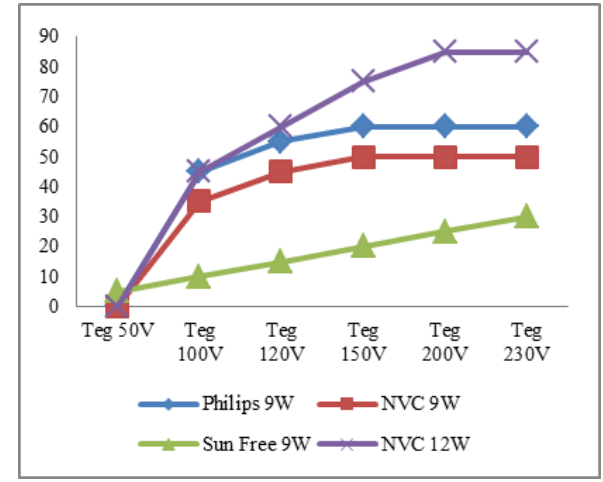

Fig. 5. 9W and 12W LED Lamp Sensitivity Profile Against Electricity Changes

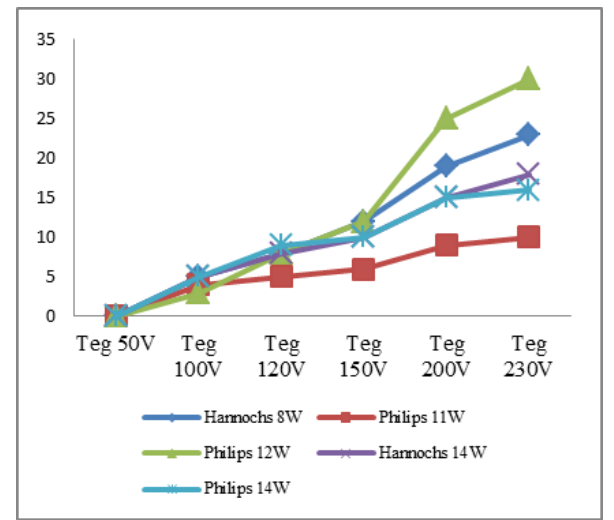

Fig. 6. ESL 8-14W Lamp Sensitivity Profile Against Electricity Changes

Based on the results of testing carried out with voltage changes supplying ESL 18W, $20 \mathrm{~W}$, and $35 \mathrm{~W}$ lights, data is obtained as shown in Figure 8. From Figure 8 it can be seen that all types indicate the type of Philips $18 \mathrm{~W}$ lamp has a relatively better sensitivity to voltage 
characteristics, where this type of lamp is able to produce light starting at a 100 Volt supply voltage. From the data illustrated, it is also seen that the $18 \mathrm{~W}$ type of hannochs lamp shows the ability to produce stronger lighting characteristics that are better when compared to the types of ESL lamps with $18 \mathrm{~W}$ up to $35 \mathrm{~W}$ tested.

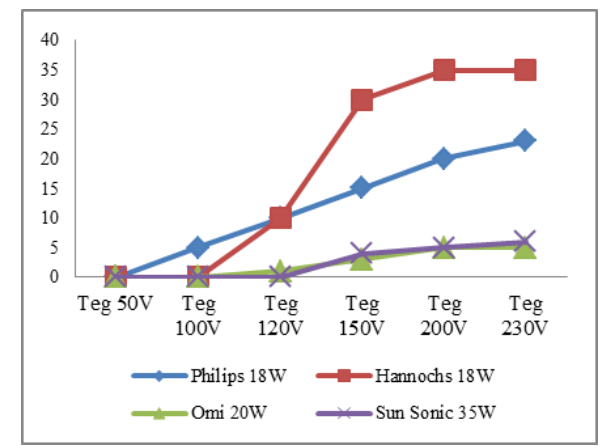

Fig. 7. ESW 18W, 20W and 35W Lamp Sensitivity Profiles Against Electricity Changes

Based on profile data in Figure 2, it can be seen that when viewed from the use of electrical power used by a lamp to produce strong lighting, the type of Philips 7W lamp and type of $12 \mathrm{~W}$ NVC lamp look more effective to produce the required light. Furthermore, if viewed from the comparison of lamp types based on their power, it can be seen that for $3 \mathrm{~W}$ and $5 \mathrm{~W}$ power for Hannochs lamps, and $4 \mathrm{~W}$ lamp power for philips lights show comparable characteristics. This means that the power used is proportional to the lighting power produced. Therefore, users can choose based on the lighting requirements needed.

In figure 3 the ESL lamp profile shows that for the type of Hannochs lamp power 14W shows a non-linear illumination with the electrical power used. The same thing is also seen in the type of $14 \mathrm{~W}$ philips power lamp. This means that lamps with a power of $14 \mathrm{~W}$ both on the types of hannochs lamps and types of Philips lamps do not produce strong lighting that is in accordance with the power used. 18L ESL lights for Hannochs type lamps and Philips type lamps show the characteristics of the comparison between the use of electric power and the same strong lighting. This means that especially for the $18 \mathrm{~W}$ ESL lamp types have the same characteristics. Meanwhile, the type of Omai lamps and sun free shows the incompatibility between the lamp labels and the use of electrical power.

Data from measurements on the types of LED and ESL lamps indicate that LED type lights provide better light efficacy when compared to the ESL type light efficacy [7]. This means that the comparison between the power used and the strong illumination produced is better in LED lights when compared to that produced in ESL lamps. Thus, the types of LED lights on the market have relatively better characteristics compared to the types of ESL lamps. LED lights and ESL types, both of which have a discrepancy between the power on the lamp label and the measured power. Power deviations between labels and measured objects in ESL lamps reach an average of $18.88 \%$, while deviations in types of LED lights averaged $9.88 \%$.

Different test results show that there are differences in the ability to produce strong light from various types of lighting that are circulating in the market, where the average LED light is capable of producing better lighting power when compared to the type of ESL lamp. The ability to accept lower voltages also differs between types of LED lights with ESL types of lights, where LED lights are more flexible in accepting voltage when compared to ESL lamp types, and there are differences in the use of electric power from various types of lighting in 
the market, where lights This type of LED uses less electric power to produce lighting power when compared to ESL lamp types.

\section{Conclusion}

Based on the results of the research obtained, it shows that there are differences in power measured by power on the pen lamp label circulating in the market, where the type of LED lamp has label power difference with a measured power usage of $9.88 \%$ and ESL lamp types having a difference of $18,88 \%$. The average LED light is capable of producing better lighting power when compared to ESL lamp types. LED lights are also more flexible in receiving lower voltage sources when compared to ESL lamp types. LED type lights use smaller electric power to produce lighting power when compared to ESL lamp types.

\section{References}

[1] H. Singh, M., Singh, G. and Singh, "Energy audit: A case study to reduce lighting cost," Asian J. Comput. Sci. Inf. Technol., vol. 2, no. 5, pp. 119 - 122, 2013.

[2] S. Mitchell, C.A., Both, A., Bourget, C.M., Kuboto, C., Lopez, R.G., Morrow, R.C., \& Runkle, "LEDs: The future of greenhouse lighting," Chron. Hortic., vol. 55, pp. 6-12, 2012.

[3] R. C. Morrow, "LED lighting in horticulture," Hort Sci., vol. 43, pp. 1947-1950, 2008.

[4] T. Agam, Bima Brilliando., Yushardi., \& Prihandono, "Pengaruh Jenis dan Bentuk Lampu terhadap Intensitas Pencahayaan dan Energi Buangan melalui Perhitungan Nilai Efikasi Luminus," J. Pendidik. Fis., vol. 3, no. 4, pp. 384-389, 2015.

[5] Y. Takei, "Energy Saving Lighting Efficiency Technologies," Q. Rev. DC. Nurses. Assoc., no. 32, pp. 59-70, 2009.

[6] \& K. Saputro, Jimy Harto., Sukmadi, Tejo., "Analisa Penggunaan Lampu LED pada Penerangan dalam Rumah," J. Transm., vol. 15, no. 1, pp. 19 - 27, 2013.

[7] C. M. Bourget, "An introduction to light-emitting diodes," Hort Sci., vol. 43, pp. 1944-1946, 2008. 